\title{
Production Analysis for Fractured Vertical Well in Coal Seam Reservoirs with Stimulated Reservoir Volume
}

\author{
Chen Li $\mathbb{D}$ \\ CNOOC Research Institute Ltd., CNOOC Building, Yard 6, Taiyanggong South Street, Chaoyang District, Beijing, China
}

Correspondence should be addressed to Chen Li; lichen1125@foxmail.com

Received 11 August 2021; Revised 17 September 2021; Accepted 27 September 2021; Published 1 November 2021

Academic Editor: Jinjie Wang

Copyright (c) 2021 Chen Li. This is an open access article distributed under the Creative Commons Attribution License, which permits unrestricted use, distribution, and reproduction in any medium, provided the original work is properly cited.

\begin{abstract}
The development and utilization of coalbed methane is of great significance to reduce carbon dioxide emission. Through the research, this paper presents a fast analytical solution method for the productivity of coalbed methane reservoir with finiteconductivity fractured well and stimulated reservoir volume region. Based on the dual-porosity flowing mechanism, combined with the Langmuir adsorb equation, Fick diffusion law, and Darcy law, a mathematical model considering diffusion in matrix and transport in natural fracture system is established, using spherical matrix to describe the transient steady-state sorption, and using cubic matrix to describe the pseudosteady-state sorption. Then, combined with the inner system and outer system, the analytical solution was obtained. Furthermore, the accuracy of the solution was validated against a numerical simulation. According to the Duhamel principle, the effect of wellbore storage and skin factor was got. Due to the SRV region, the linear flow and radial flow will appear before the pressure wave reach the outer region. And then, based on the pressure analysis result, we will have made the sensitivity analysis with different influence parameter. The result reveals that storage coefficient and conductivity factor mainly influence the early time; the permeability ratio and dimensionless SRV region radius mainly influence the property of SRV region. Finally, the analytical solution of the new model was applied to field history match. This model takes into account the adsorption and desorption characteristics of coalbed methane, as well as the SRV zones generated during fracturing. The calculation speed of the new model is increased while the calculation accuracy is retained, and the intensity of software application is reached. The model achieves the purpose of rapid evaluation and accurate prediction of gas well productivity and obtains a set of productivity evaluation method suitable for coalbed methane reservoir with fractured vertical well, which provides a basis for the development and productivity evaluation of coalbed methane reservoir in domestic and international cooperation.
\end{abstract}

\section{Introduction}

Coalbed methane refers to methane gas in coal seams. There are two main ways of occurrence of coalbed methane in coal seams: free and adsorption. The existence form of free gas is the same as conventional gas reservoir. Adsorbed gas is adsorbed in the matrix of coal seam in a dynamic equilibrium way. In the process of exploitation, with the decline of formation pressure, the adsorbed gas is gradually resolved from the adsorbed state and becomes free gas. Therefore, when analyzing the pressure change in coal seam, the desorption of adsorbed gas and the migration of free gas must be considered $[1,2]$.
The main method to develop the coalbed methane was stimulated reservoir volume (SRV) and hydraulic fractured. Due to the fragility of coal seam, with the fracturing fluid injected in to the formation, it will crush the coal around the injection point. Based on this process, the seepage environment around the injection point has been changed. Especially the stimulated reservoir volume, its purpose was improving the seepage environment around the injection point. With the fracture width decrease and effective length increase, we cannot ignore the fracture conductivity. So, it is necessary to establish the new model that has the different seepage environment in the inner region and outer region with the finite-conductivity fracture. 
The pressure analysis model and productivity analytical solution model of coalbed methane are based on the classical dual-porosity model of conventional gas reservoirs proposed by Warren-Root's regular hexahedron model (1963) [3], De Swaan-A' spherical model (1976) [4], and Kazemi's stick model (1992) [5]. In the Laplace space, production multiplied by the pressure is equal to the image variable of Laplace transformation. So, mathematically, pressure analysis is actually productivity analysis [6, 7]. At present, the main means of pressure analysis and productivity evaluation are numerical simulation and analytical solution simulation [7-9]. Anbarci et al. introduced Langmuir isothermal adsorption equation to describe the desorption process of adsorbed gas in coalbed methane reservoir and introduced Fick diffusion law to describe the diffusion process of free gas in matrix [1]. For the fractured well, Gringarten et al. [10] studied the pressure performance during the production process and type curve analysis. In their model, the gas reservoirs are averaged, and the hydraulic fracture is the infinite-conductivity fracture. However, for the soft reservoir of coalbed methane, the attribute of the reservoir is nonmean, fracture conductivity is often small, and its conductivity factor cannot reach the magnitude of infinite conductivity. To solve this problem, Cinco-Ley et al. [11, 12] developed a semianalytical solution. In terms of production prediction, Clarkson et al. [13] presented typical production curves for fractured vertical wells and staged fractured horizontal wells in coalbed methane reservoirs. Zhao et al. [14] use the composite model to discuss the infiniteconductivity fracture with SRV region in coalbed methane and get the pressure behavior in the button hole. Wang et al. [15] use the semianalytical simulation to calculate the production rate with complex fracture network and stresssensitive conductivity. [16] use source and Green's function to establish framework model for complex fracture network. Huang [17] using the point source function and pressure superposition theory gained the mathematical model of production decline. Zhu [18] proposed an automatic segmentation trend tracking model for the CBM production forecast. His work based on the production data and is more robust for the complex production condition. Yan et al. [19] gained the semianalytical mathematical model that considers the self-regulating effects of coal reservoirs. Jiang et al. [20] studied the unsteady productivity model of multilateral horizontal wells based on point source function. The stress sensitivity effect is considered in the model. Wu et al. [21] studied the pressure performance of multistage fractured horizontal well with the rectangular SRV region and adsorbed gas. Shang et al. [22] studied the gas-water twophase flow in coalbed with single layer and multilayer. The influence of coal seam pressure difference on single well production is demonstrated. Tian et al. [23] studied the flow characteristics of horizontal well with multiple fracture wings. The semianalytical solution model of horizontal well with multiple fracture wings is established, and the flow stage of the model is defined. The influencing factors of production capacity are evaluated.

Most of the above literature cannot completely describe the model with all factor. Especially the stimulated reservoir volume in coal seam, very few people work with it. However, the elastic modulus of coal seam is small, and natural fractures are developed in coal seam, even hydraulic fracturing always generates a network fracture around the well, not to mention stimulated reservoir volume. On the other hand, with the fracture width decrease and length increase, we cannot ignore the fracture conductivity. So, SRV model with the finite-conductivity fracture in the coalbed was the important model for the production; it is a suitable model for the really geologic condition. In order to accurately describe the characteristics of coalbed methane reservoirs, the purpose of this paper is to establish a productivity evaluation model considering hydraulic fractures and SRV region.

A new mathematical model in this paper was established and solved. The new model comprehensively considers the desorption and adsorption effect of coalbed methane, the diffusion process of matrix, and the conductivity of fracture. Firstly, the transient steady-state, pseudosteady-state sorption, and diffusion models will be discussed in this specific flow model. Secondly, the analytical results of the model are verified by a commercial numerical simulator. The degenerate model of the model is verified by the classical model. Thirdly, the different diffusion models were analyzed. There is different pressure performance with different flow stage between the transient steady-state and pseudosteadystate sorption and diffusion models. Finally, the new model is used to analyze the bottom hole pressure and flow rate of production wells in the southern Qinshui Basin, and the calculated results are well fitted.

\section{Mathematical Models and Analytical Solutions}

2.1. Methodology. In order to simplify the seepage model, important assumptions need to be made:

(1) The reservoir is cylindrical; the producing well is located in the center of the gas reservoir. The well perforated throughout the reservoir

(2) The inner boundary has either constant pressure or constant flow rate

(3) The reservoir has the cylindrical SRV region, using the composite model to describe the reservoir, and the inner region can be treated as the SRV region caused by hydraulic fracturing (Figure 1)

(4) Gas is adsorbed in the matrix of coal seam under original condition; as the development goes on, the gas desorption from the matrix diffuses into the natural fracture system, flows into the hydraulic fracture, and eventually flows into the wellbore (Figure 2)

(5) Hydraulic fractures are finite-conductivity fracture (Figure 3)

(6) The sorption and diffusion model of the matrix divide into the unsteady state and pseudosteady state, the unsteady state uses spherical matrix 


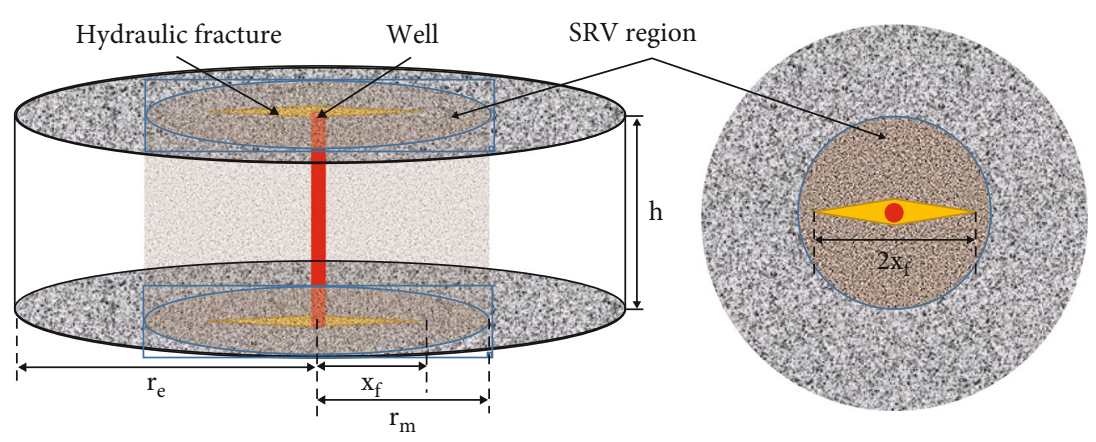

FIGURE 1: Reservoir model with SRV.

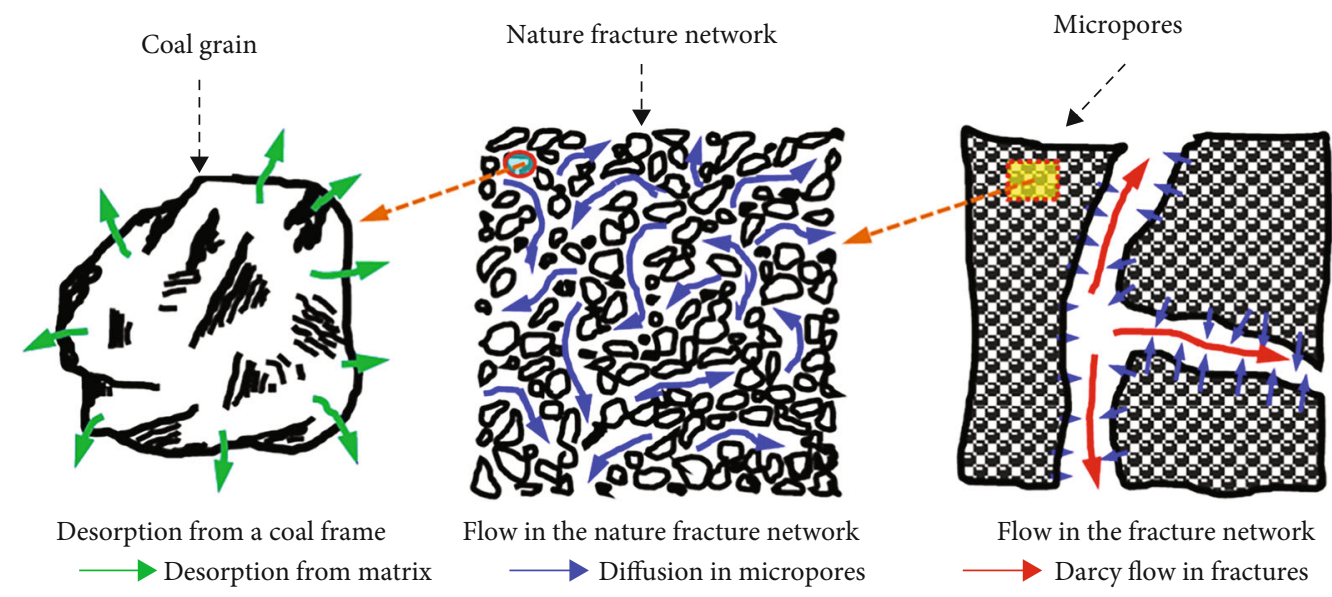

FIgure 2: Desorption and diffusion in the matrix and Darcy flow in the fracture.

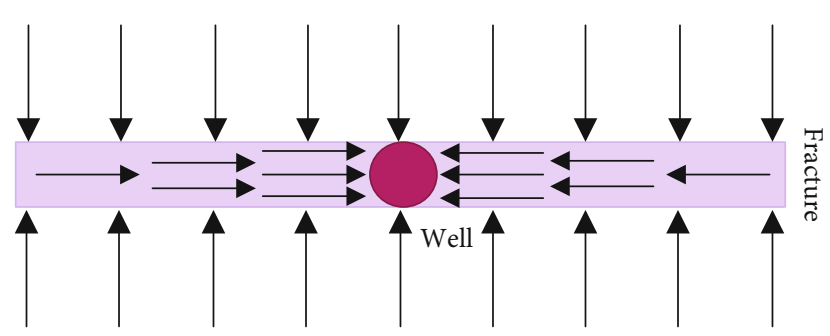

Figure 3: The flow rate distribution in the finite-conductivity fracture.

expressed and the pseudosteady state uses the cube matrix expressed (Figure 4)

(7) The initial reservoir is uniform

(8) Skin effect and wellbore storage effect are not negligible

2.2. Model Establishment and Solution. Anbarci and Ertekin [1] proposed a coalbed methane reservoir seepage model based on the conventional double-porosity model. However, this model can only consider the mean gas reservoir, and its hydraulic fractures are infinite-conductivity fractures. In this article, fractured well with finite conductivity in coalbed with stimulated reservoir volume region is discussed, using the spherical matrix to describe the transient steady-state sorp- tion and the cubic matrix to describe the pseudosteadystate sorption.

2.3. Modeling Flow in the Nature Fracture. Different from conventional gas reservoirs, free gas and desorbed adsorbed gas flow together in coalbed methane reservoirs. This makes the material balance equation become nonlinear equation.

The control equation in the nature fracture system in SRV region:

$$
\frac{1}{r} \frac{\partial}{\partial r}\left(r \frac{p_{1 n f}}{\mu_{1} Z} \frac{\partial p_{1 n f}}{\partial r}\right)=\frac{\phi_{1 n f} c_{g} p_{1 n f}}{k_{1 n f} Z} \frac{\partial p_{1 n f}}{\partial t}+\frac{p_{s c} T}{k_{1 n f} T_{s c}} \frac{\partial V_{1 n f}}{\partial t}
$$

The control equation in the nature fracture system in outer region:

$$
\frac{1}{r} \frac{\partial}{\partial r}\left(r \frac{p_{2 n f}}{\mu_{2} Z} \frac{\partial p_{2 n f}}{\partial r}\right)=\frac{\phi_{2 n f} c_{g} p_{2 n f}}{k_{2 n f} Z} \frac{\partial p_{2 n f}}{\partial t}+\frac{p_{s c} T}{k_{2 n f} T_{s c}} \frac{\partial V_{2 n f}}{\partial t}
$$

For a well with an infinite, closed, or constant pressure boundary, we have 


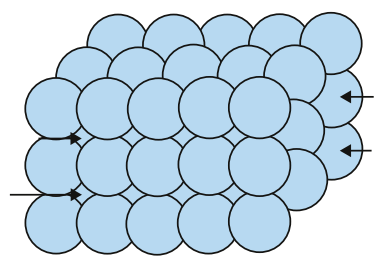

(a)

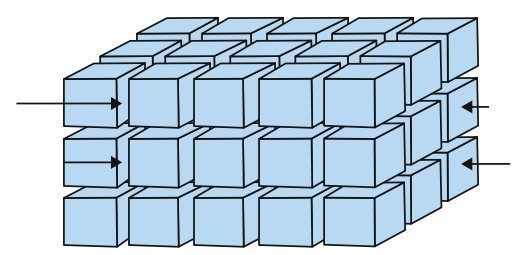

(b)

FIGURE 4: Unsteady-state (a) and pseudosteady-state (b) sorption/diffusion.

$$
\begin{aligned}
\left.p_{2 n f}(r, t)\right|_{r \longrightarrow \infty} & =p_{i} \text { infinite boundary, } \\
\left.\frac{\partial p_{2 n f}}{\partial r}\right|_{r=r e} & =0 \text { closed boundary, } \\
\left.p_{2 n f}\right|_{r=r e} & =p_{i} \text { constant pressure boundary. }
\end{aligned}
$$

The well was produced at constant flow rate:

$$
\left.\frac{k_{1 n f} h}{\mu_{1}}\left(r \frac{\partial p_{1}}{\partial r}\right)\right|_{r \longrightarrow 0}=q_{s c} \frac{Z p_{s c} T}{p_{1 n f} T_{s c}} \frac{k_{2 n f}}{\Lambda L^{2}} .
$$

At the junction between the SRV region and outer region:

$$
\begin{gathered}
\left.p_{1 n f}(r, t)\right|_{r=r_{m}}=\left.p_{2 n f}(r, t)\right|_{r=r_{m}}, \\
\left.p_{1 n f} \frac{\partial p_{1 n f}}{\partial r}\right|_{r=r_{m}}=\left.\frac{p_{1 n f}}{M_{12}} \frac{\partial p_{2 n f}}{\partial r}\right|_{r=r_{m}} .
\end{gathered}
$$

The initial condition of natural fracture system:

$$
p_{1 n f}(r, 0)=p_{2 n f}(r, 0)=p_{i} .
$$

According to Al-Hussainy et al. [24] and Agarwal [25], the pseudopressure and pseudotime are defined as

$$
\begin{aligned}
\psi & =2 \int_{0}^{p} \frac{p}{\mu Z} d p, \\
t_{a} & =\int_{t_{0}}^{t} \frac{1}{\mu c_{g}} d t .
\end{aligned}
$$

The dimensionless group is defined as follows:

$$
\begin{aligned}
t_{D} & =\frac{k_{2 n f} t_{a}}{\Lambda L^{2}}, \psi_{1 n f D}=\frac{k_{2 n f} h T_{s c}}{p_{s c} T} \Delta \psi_{1 n f}, M_{12}=\frac{k_{1 n f}}{k_{2 n f}}, r_{m D} \\
= & \frac{r_{m}}{L_{f}}, \omega_{1}=\frac{\phi_{1} \mu_{g i} c_{t 1}}{\Lambda}, r_{D m}=\frac{r_{m}}{R_{m}}, \omega_{2}=\frac{\phi_{2} \mu_{g i} c_{t 2}}{\Lambda}, \\
\sigma & =\frac{V_{L} \psi_{L}\left(p_{n f}\right)}{\left[\psi_{L}\left(p_{n f}\right)+\psi\left(p_{n f}\right)\right]\left[\psi_{L}\left(p_{n f}\right)+\psi\left(p_{i}\right)\right]} \frac{q_{s c} p_{s c} T}{k_{2 n f} h T_{s c}}, r_{D}=\frac{r}{L_{f}},
\end{aligned}
$$

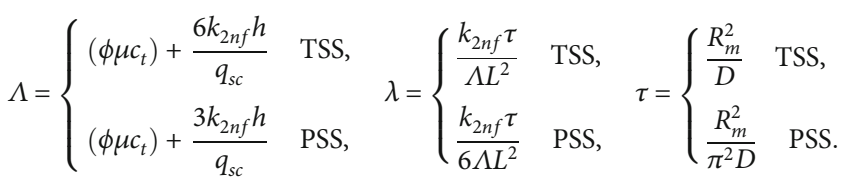

Sorption equation for transient steady state and pseudosteady state:

$$
\begin{aligned}
& \frac{\partial V}{\partial t}=\left.\frac{3 D}{R_{m}} \frac{\partial V}{\partial r_{m}}\right|_{r_{m}=R_{m}} \text { for TSS, } \\
& \frac{\partial V}{\partial t}=\frac{6 D \pi^{2}}{R_{m}^{2}}\left(V_{E}-V\right) \text { for PSS. }
\end{aligned}
$$

Combined with the diffusion equation, the control equation in the nature fracture system becomes as follows.

Inner boundary:

$$
\frac{1}{r_{D}} \frac{\partial}{\partial r_{D}}\left(r_{D} \frac{\partial \tilde{\psi}_{1 n f}}{\partial r_{D}}\right)=f_{1}(s) \tilde{\psi}_{1 n f} .
$$

Outer boundary:

$$
\frac{1}{r_{D}} \frac{\partial}{\partial r_{D}}\left(r_{D} \frac{\partial \tilde{\psi}_{2 n f}}{\partial r_{D}}\right)=f_{2}(s) \tilde{\psi}_{2 n f},
$$

where

$$
f_{1}(s)=\left\{\begin{array}{l}
\frac{\omega_{1} s}{M_{12}}+\frac{\beta_{1} \sigma}{\lambda M_{12}}[\sqrt{\lambda s} \operatorname{coth}(\sqrt{\lambda s})-1] \quad \text { TSS } \\
\frac{\omega_{1} s}{M_{12}}+\frac{\beta_{1}}{M_{12}} \frac{\sigma s}{\lambda s+1} \quad \text { PSS }
\end{array}\right.
$$

$$
\begin{aligned}
& f_{2}(s)=\left\{\begin{array}{l}
\omega_{2}+\frac{\beta_{2} \sigma}{\lambda}[\sqrt{\lambda s} \operatorname{coth}(\sqrt{\lambda s})-1] \text { TSS, } \\
\omega_{2} s+\beta_{2} \frac{\sigma s}{\lambda s+1} \text { PSS, }
\end{array}\right. \\
& \beta_{1}=\left(1-\omega_{1}-\omega_{2}\right)\left(1-\phi_{1}\right) \text {, } \\
& \beta_{2}=\left(1-\omega_{1}-\omega_{2}\right)\left(1-\phi_{2}\right) \text {. }
\end{aligned}
$$

Through Equations (13) and (14), combined with the definite condition, we can get the solution as follows: 


$$
\begin{aligned}
& \tilde{\psi}_{1 n f}=A_{1} I_{0}\left(\sqrt{f_{1}(s)} r_{D}\right)+B_{1} K_{0}\left(\sqrt{f_{1}(s)} r_{D}\right) \\
& \tilde{\psi}_{2 n f}=A_{2} I_{0}\left(\sqrt{f_{2}(s)} r_{D}\right)+B_{2} K_{0}\left(\sqrt{f_{2}(s)} r_{D}\right) .
\end{aligned}
$$

We want to get the pressure performance at bottle hole. So, combining with the inner boundary condition and interface condition, we can get the $A_{1}$ and $B_{1}$.

In the infinitely boundary:

$$
\begin{aligned}
& B_{1}=q_{s c} \frac{p_{s c} T k_{2 n f}}{T_{s c} \Lambda L^{2} k_{1 n f} h}, \\
& A_{1}=B_{1} \frac{M_{12} \sqrt{f_{1}(s)} K_{1}\left(\sqrt{f_{1}(s)} r_{m D}\right) K_{0}\left(\sqrt{f_{2}(s)} r_{m D}\right)-\sqrt{f_{2}(s)} K_{0}\left(\sqrt{f_{1}(s)} r_{m D}\right) K_{1}\left(\sqrt{f_{2}(s)} r_{m D}\right)}{M_{12} \sqrt{f_{1}(s)} I_{1}\left(\sqrt{f_{1}(s)} r_{m D}\right) K_{0}\left(\sqrt{f_{2}(s)} r_{m D}\right)+\sqrt{f_{2}(s)} I_{0}\left(\sqrt{f_{1}(s)} r_{m D}\right) K_{1}\left(\sqrt{f_{2}(s)} r_{m D}\right)} .
\end{aligned}
$$

In the closed boundary and constant pressure boundary, it has the same $B_{1}$ with the infinitely boundary, the $A_{1}$ as

$$
A_{1}=B_{1} \frac{K_{0}\left(\sqrt{f_{1}(s)} r_{m D}\right)+\varepsilon \sqrt{f_{1}(s)} K_{1}\left(\sqrt{f_{1}(s)} r_{m D}\right)}{\varepsilon \sqrt{f_{1}(s)} I_{1}\left(\sqrt{f_{1}(s)} r_{\mathrm{m} D}\right)-I_{0}\left(\sqrt{f_{1}(s)} r_{\mathrm{m} D}\right)},
$$

where

$$
\begin{aligned}
& \varepsilon=\frac{M_{12}\left(\eta I_{0}\left(\sqrt{f_{2}(s)} r_{\mathrm{m} D}\right)+K_{0}\left(\sqrt{f_{2}(s)} r_{m D}\right)\right)}{\eta \sqrt{f_{2}(s)} I_{1}\left(\sqrt{f_{2}(s)} r_{\mathrm{m} D}\right)-\sqrt{f_{2}(s)} K_{1}\left(\sqrt{f_{2}(s)} r_{m D}\right)}, \\
& \eta_{c b}=\frac{K_{1}\left(\sqrt{f_{2}(s)} r_{\mathrm{e} D}\right)}{I_{1}\left(\sqrt{f_{2}(s)} r_{\mathrm{e} D}\right)} .
\end{aligned}
$$$$
\eta_{c p b}=-\frac{K_{0}\left(\sqrt{f_{2}(s)} r_{\mathrm{eD}}\right)}{I_{0}\left(\sqrt{f_{2}(s)} r_{\mathrm{eD}}\right)} .
$$

Generally, we can get the solution for the nature fracture system as

$$
\tilde{\psi}_{1 n f}=\frac{p_{s c} T q_{s c}}{T_{s c} k_{1 n f} h}\left(K_{0}\left(\sqrt{f_{1}(s)} r_{D}\right)+\Omega I_{0}\left(\sqrt{f_{1}(s)} r_{D}\right)\right) .
$$

According to the dimensionless group,

$$
\tilde{\psi}_{1 D n f}=\int_{-1}^{1} \frac{1}{M_{12}} \tilde{q}_{D n f}\left(K_{0}\left(\sqrt{f_{1}(s)} r_{D}\right)+\Omega I_{0}\left(\sqrt{f_{1}(s)} r_{D}\right)\right) d r_{D},
$$

The constant pressure boundary has the same theory with the closed boundary, only different with $\eta$ :

where

$$
\Omega=\left\{\begin{array}{l}
\frac{M_{12} \sqrt{f_{1}(s)} K_{1}\left(\sqrt{f_{1}(s)} r_{m D}\right) K_{0}\left(\sqrt{f_{2}(s)} r_{m D}\right)-\sqrt{f_{2}(s)} K_{0}\left(\sqrt{f_{1}(s)} r_{m D}\right) K_{1}\left(\sqrt{f_{2}(s)} r_{m D}\right)}{M_{12} \sqrt{f_{1}(s)} I_{1}\left(\sqrt{f_{1}(s)} r_{m D}\right) K_{0}\left(\sqrt{f_{2}(s)} r_{m D}\right)+\sqrt{f_{2}(s)} I_{0}\left(\sqrt{f_{1}(s)} r_{m D}\right) K_{1}\left(\sqrt{f_{2}(s)} r_{m D}\right)} \quad \text { infinitely boundary, } \\
\left.\frac{K_{0}\left(\sqrt{f_{1}(s)} r_{m D}\right)+\varepsilon_{x} \sqrt{f_{1}(s)} K_{1}\left(\sqrt{f_{1}(s)} r_{m D}\right)}{\varepsilon_{x} \sqrt{f_{1}(s)} I_{1}\left(\sqrt{f_{1}(s)} r_{\mathrm{mD}}\right)-I_{0}\left(\sqrt{f_{1}(s)} r_{\mathrm{mD}}\right)}\right|_{x=c b \text { or } c p b} \quad \text { closed and constant pressure boundary. }
\end{array}\right.
$$




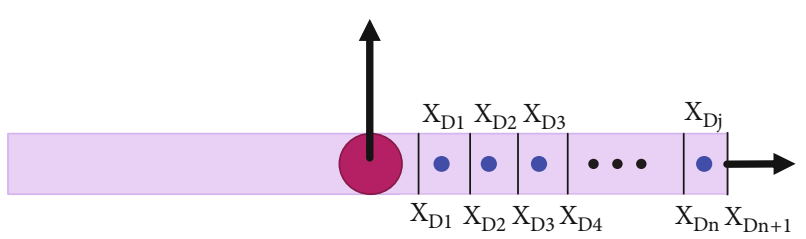

FIGURE 5: Disperse the finite-conductivity fracture.

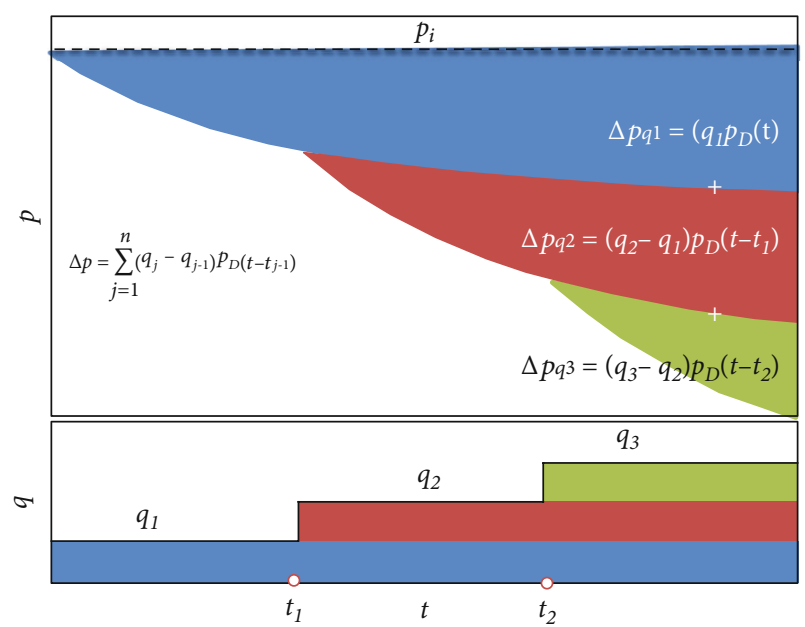

FIgURE 6: The process of Duhamel convolution.

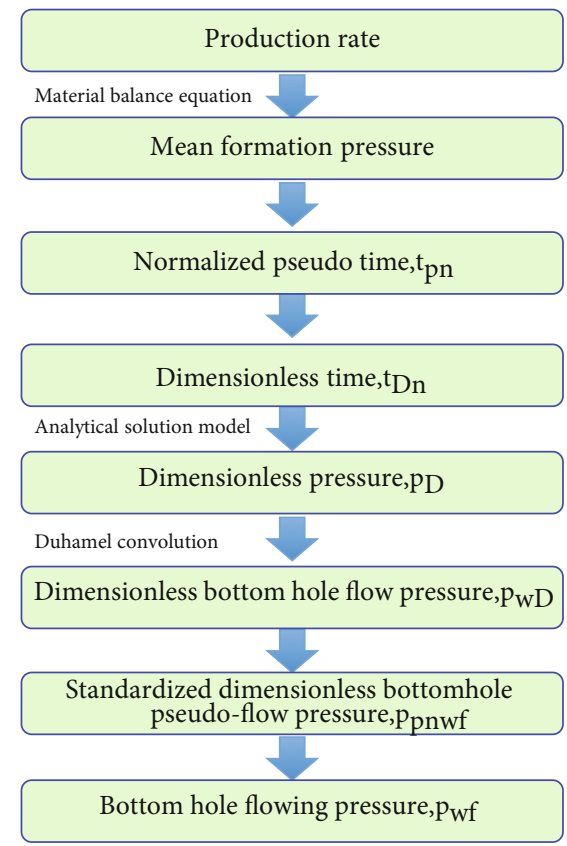

FIgURE 7: The Duhamel convolution is used to obtain pressure.

2.4. The Model Flow in the Hydraulic Fracture. In a similar way to Equation (23), we can get the control equation in the hydraulic fracture. In the finite-conductivity fracture, the $\tilde{q}_{D n f}(s)$ was different with different place in the hydraulic fracture (Figure 3).

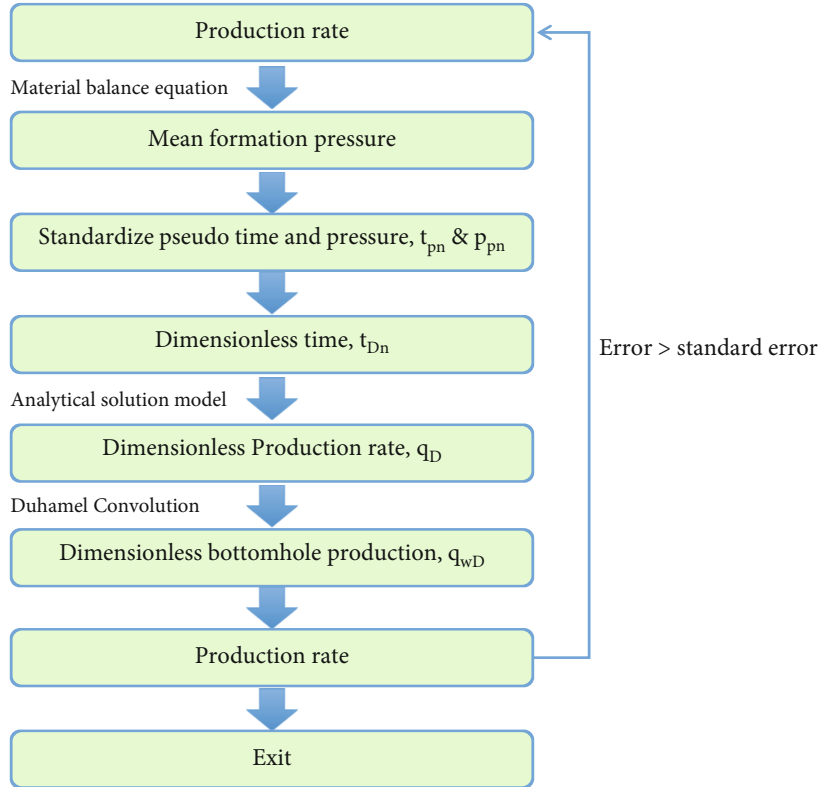

FIgURE 8: The Duhamel convolution is used to obtain production rate.

TABLE 1: The basic data to verify the result.

$$
\begin{aligned}
& \tau=328990 \mathrm{hr} \\
& \mu=0.01082 \mathrm{cp} \\
& T=530 \mathrm{R} \\
& q_{\mathrm{sc}}=0.2 \mathrm{MMscf} / \mathrm{d} \\
& p_{\text {ic }}=447.7 \mathrm{psia} \\
& \varphi=0.01 \\
& x_{\mathrm{f}}=100 \mathrm{ft} \\
& \frac{\partial^{2} \tilde{\psi}_{D n f}}{\partial x_{D}^{2}}+\left.\frac{2}{C_{f D}} \frac{\partial \tilde{\psi}_{D}}{\partial y_{D}}\right|_{y_{D}=0}=0 \quad 0<x_{D}<1 \\
& \tilde{q}_{D h f}\left(x_{D}, s\right)=-\left.\frac{2}{\pi} \frac{\partial \tilde{\psi}_{D}}{\partial y_{D}}\right|_{y_{D}=0}, \\
& \left.\frac{\partial \tilde{\psi}_{f D}}{\partial x_{D}}\right|_{x_{D}=0}=-\frac{\pi}{s C_{f D}} .
\end{aligned}
$$$$
r_{\mathrm{w}}=0.5 \mathrm{ft}
$$$$
c=0.002234 \mathrm{psia}^{-1}
$$$$
z=0.9404
$$$$
V_{\mathrm{L}}=18.632 \mathrm{scf} / \mathrm{ft}^{3}
$$$$
k=26 \mathrm{md}
$$$$
h=6 \mathrm{ft}
$$$$
P_{\mathrm{L}}=167.58 \mathrm{psi}
$$

Through Equations (25), (26), and (27), we can get

$$
\tilde{\psi}_{w D}-\tilde{\psi}_{D n f}\left(x_{D}, y_{D}=0, s\right)=\frac{\pi}{s C_{f D}}\left[x_{D}-s \int_{0}^{x_{D}} \int_{0}^{\eta} \bar{q}_{D h f} d x_{D} d \eta\right] .
$$

Dispersing Equation (28) according to Figure 5, 


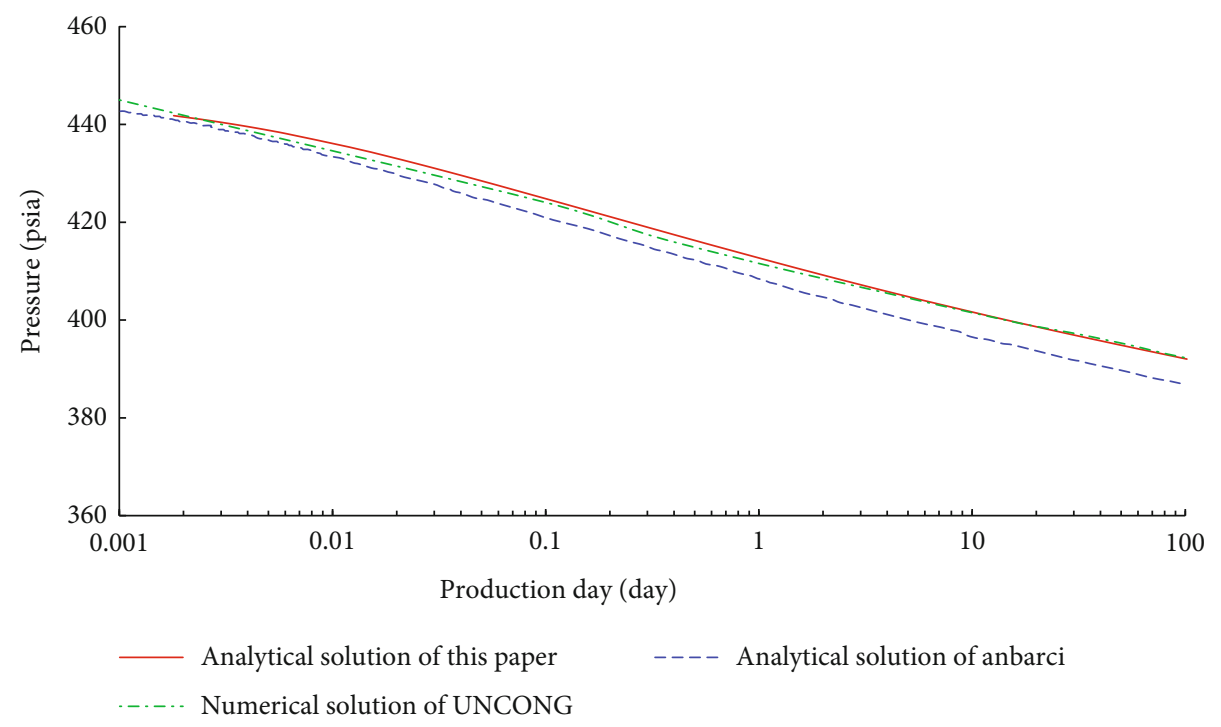

FIGURE 9: The comparison between classical literature and commercial numerical simulator.

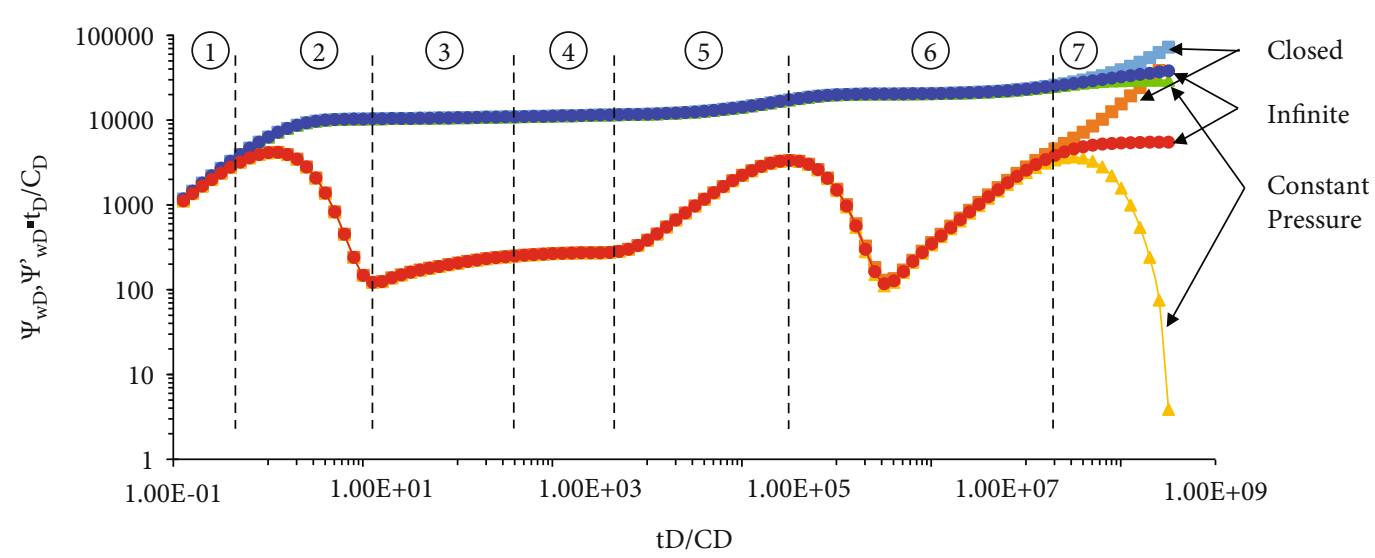

Figure 10: Flow stage divided for rectangle coal reservoirs.

$$
\begin{gathered}
{\left[\begin{array}{c}
\left.\tilde{\psi}_{w D}-\frac{1}{2} \sum_{i=1}^{n} \tilde{q}_{f D i} \int_{x_{D i}}^{x_{D i+1}}\left[K_{0}\left(\left|\bar{x}_{D j}+\xi\right| \sqrt{f(s)}\right)+K_{0}\left(\left|\bar{x}_{D j}-\xi\right| \sqrt{f(s)}\right)\right] d \xi+\right] \\
\frac{\pi}{C_{f D}}\left\{\sum_{i=1}^{j} \tilde{q}_{f D i}\left[0.5 \Delta x_{D}{ }^{2}+\Delta x_{D}\left(\bar{x}_{D j}-i \Delta x_{D}\right)\right]+\tilde{q}_{f D j} \frac{\Delta x_{D}^{2}}{8}\right\}
\end{array}\right]} \\
=\frac{\pi}{s C_{f D}} x_{D} .
\end{gathered}
$$

In the Laplace space, the sum of all the flow rate in every part is $1 / s$ :

$$
\Delta x \sum_{k=1}^{n} \tilde{q}_{D h f k}(s)=\frac{1}{s} .
$$

To obtain the solution including wellbore storage and skin effect, we need the relationship given as
TABle 2: The basic data of the curves.

\begin{tabular}{lccc}
\hline$\Phi_{1}=0.2$ & $\omega_{1}=0.5$ & $M_{12}=10$ & $r_{\mathrm{md}}=10$ \\
$\Phi_{2}=0.1$ & $\omega_{2}=0.1$ & $\mathrm{sk}=1$ & $\lambda=1000$ \\
$C_{\mathrm{fd}}=10 \pi$ & $C_{\mathrm{D}}=0.0001$ & $r_{\mathrm{ed}}=60$ & $\sigma=100$ \\
\hline
\end{tabular}

$$
\tilde{\psi}_{w D}=\frac{1}{s^{2} C_{D}+s /\left[s \tilde{\psi}_{w D}(s)+S_{k}\right]} .
$$

2.5. History Matching and Duhamel Convolution. In the process of solving the theoretical analytical solution, it is necessary to assume that the inner boundary condition is constant to obtain the particular solution of the analytical solution. But in the actual production process, because of the influence of production conditions, the output and pressure are generally changed. Duhamel convolution is required to superimpose varying production or pressure. Theoretical analytical solutions under variable yield and pressure can be obtained. The theoretical analytical solution is fitted with 


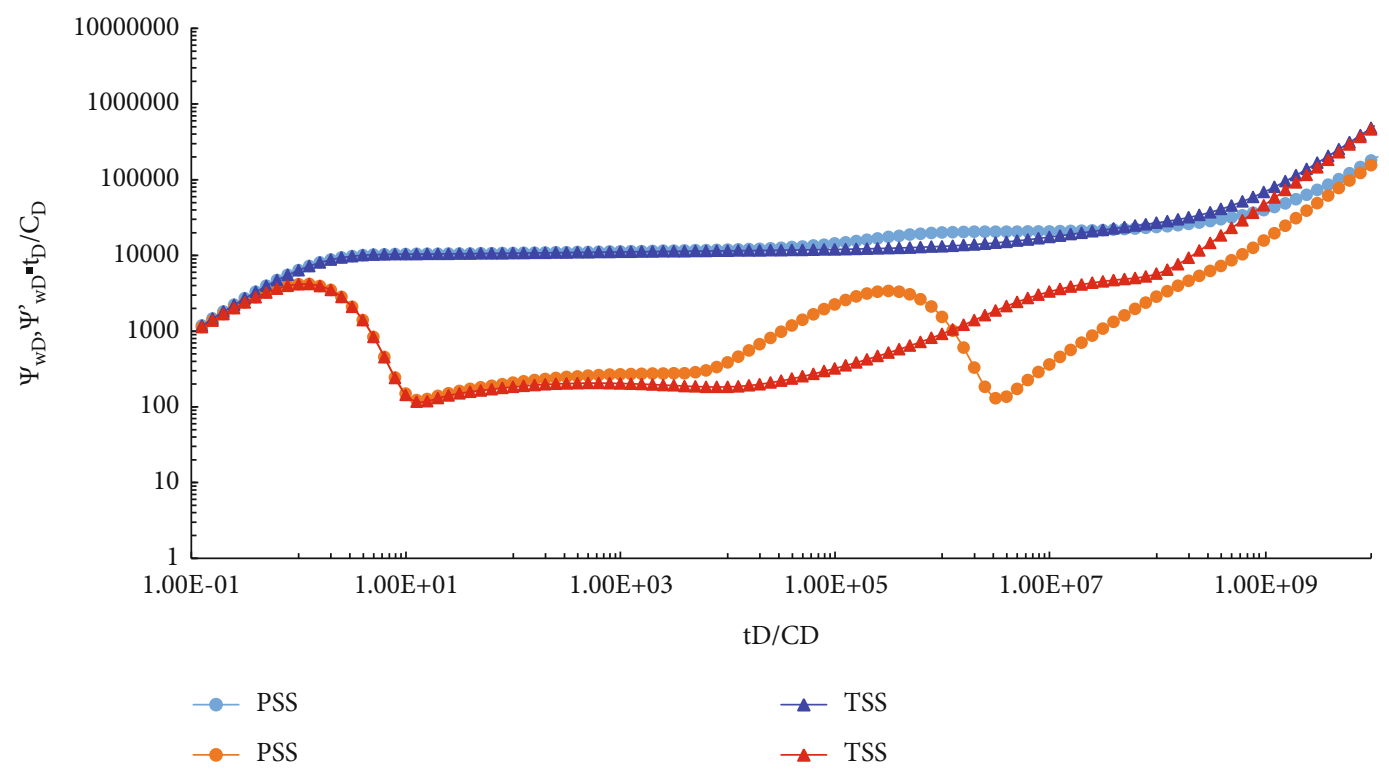

FIGURE 11: Comparison with the transient steady-state and pseudosteady-state models.

TABLE 3: Basic data of production well.

\begin{tabular}{lccc}
\hline$p_{\text {ic }}(\mathrm{psia})$ & 160 & $s$ & 0.12 \\
$k_{\text {in }}(\mathrm{md})$ & 6.13 & $k_{\text {out }}(\mathrm{md})$ & 3 \\
$\rho_{\mathrm{b}}\left(\mathrm{g} / \mathrm{cm}^{3}\right)$ & 1.47 & $\mathrm{FCD}$ & 100 \\
$r_{\text {in }}(\mathrm{ft})$ & 800 & $r_{\text {out }}(\mathrm{ft})$ & 840 \\
$h(\mathrm{ft})$ & 21.3 & $C_{\mathrm{t}}\left(\mathrm{psi}^{-1}\right)$ & 0.025 \\
$R_{\mathrm{w}}(\mathrm{ft})$ & 0.3 & $T(\mathrm{~F})$ & 57.2 \\
$\varphi$ & 0.12 & $V_{\mathrm{L}}(\mathrm{scf} / \mathrm{ton})$ & 318 \\
$L_{\mathrm{f}}(\mathrm{ft})$ & 262.5 & $P_{\mathrm{L}}(\mathrm{psi})$ & 116.03 \\
\hline
\end{tabular}

the actual production data. On the basis of fitting, the productivity evaluation and production forecast of gas well are finally realized (Figure 6).

The principle of variable pressure yield calculation or variable pressure yield calculation is similar; the only difference is that in variable pressure yield calculation, as the yield is unknown, it is necessary to assume a yield to calculate the average pressure, and the final output needs to be calculated iteratively (Figures 7 and 8).

2.6. Model Verification. Due to the complexity of the model considered in this paper, there is no classical literature to compare. On the one hand, the model presented in this paper is reduced to a simpler mean value and infinite diversion fracture model for comparison with Anbarci's work (1992). For comparison purposes, we set a large enough fracture conductivity factor and same permeability with inner and outer region. On the other hand, a commercial simulator (UNCONG) [26] is used to build the model same with Anbarci's work, and the analytical solution results in this paper are compared with those in a commercial numerical simulator. Basic data from Anbarci's paper are listed in Table 1.

Comparison with the analytical solution of Anbarci and solution from this paper was better fitting with the numeri- cal solution (Figure 9). Anbarci's solution was relatively small compared with the numerical solution.

\section{Result and Discussion}

3.1. Flow State Analysis for Composite Coal Reservoirs. Because of the composite, the pressure will through the SRV region firstly and then through the outer region. Under this condition, the flow state will differ from the homogeneous coal seam. It can be divided into seven stages (Figure 10). The value of the figure is shown in Table 2.

The flow stage divides its characteristics as follows:

(1) Wellbore storage stage. The seepage characteristic curve of coalbed methane reservoir in this stage is consistent with that of conventional gas reservoir

(2) Transition stage of wellbore storage. Wellbore storage effect gradually decreases. Because of the high permeability in the inner zone, the formation fluid flow is radial flow. Formation fluid flows from the SRV zone to the wellbore

(3) Linear flow in SRV region. The duration time of this stage always short. Sometimes, it was concealed by the wellbore storage stage when the $C_{\mathrm{D}}$ was large. The duration time depends on the length of the fracture and the $C_{\mathrm{D}}$

(4) Radial flow in SRV region. This stage will appear when the ratio of the SRV region radius and the fracture length reach the relatively large level. The characteristic of this stage was the horizontal line. The value of this line was $1 /\left(2 \times M_{12} \times C_{D}\right)$

(5) Linear flow in coal seam. When the pressure wave reaches the outer region, the linear flow in the whole reservoir appeared. The characteristic of this stage 


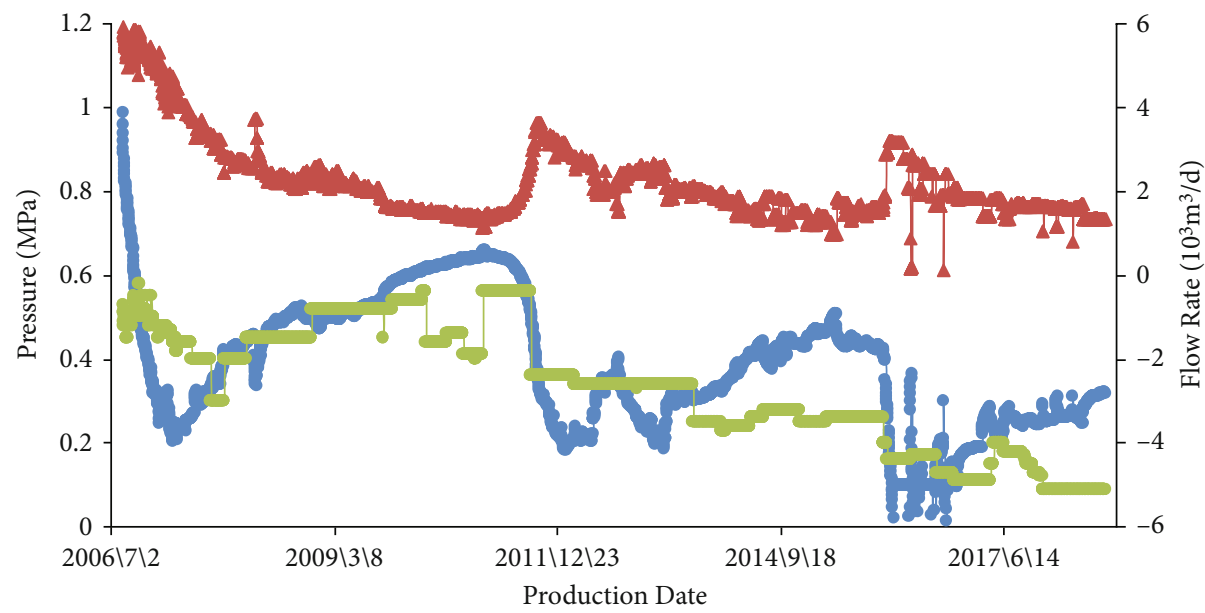

$\rightarrow$ Calculated pressure( $\mathrm{MPa})$

- Field pressure(MPa)

$\neg$ Field production rate $\left(10^{3} \mathrm{~m}^{3} / \mathrm{d}\right)$

(a) Bottom hole pressure history fitting

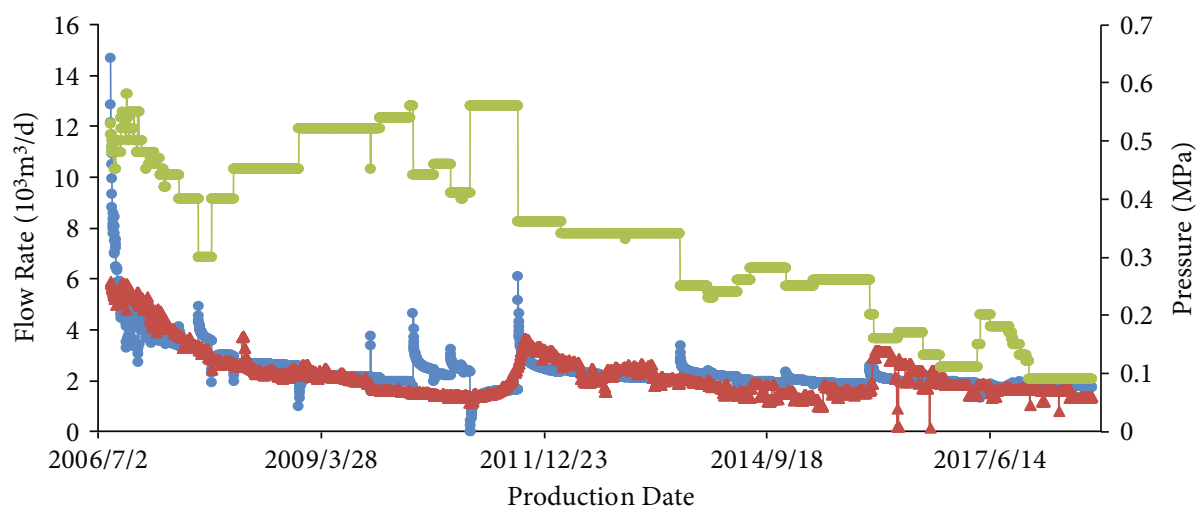

$\rightarrow$ Calculated Rate $\left(10^{3} \mathrm{~m}^{3} / \mathrm{d}\right)$

$\triangle$ Field Rate $\left(10^{3} \mathrm{~m}^{3} / \mathrm{d}\right)$

$\rightarrow$ Field Pressure(MPa)

(b) Flow rate history fitting

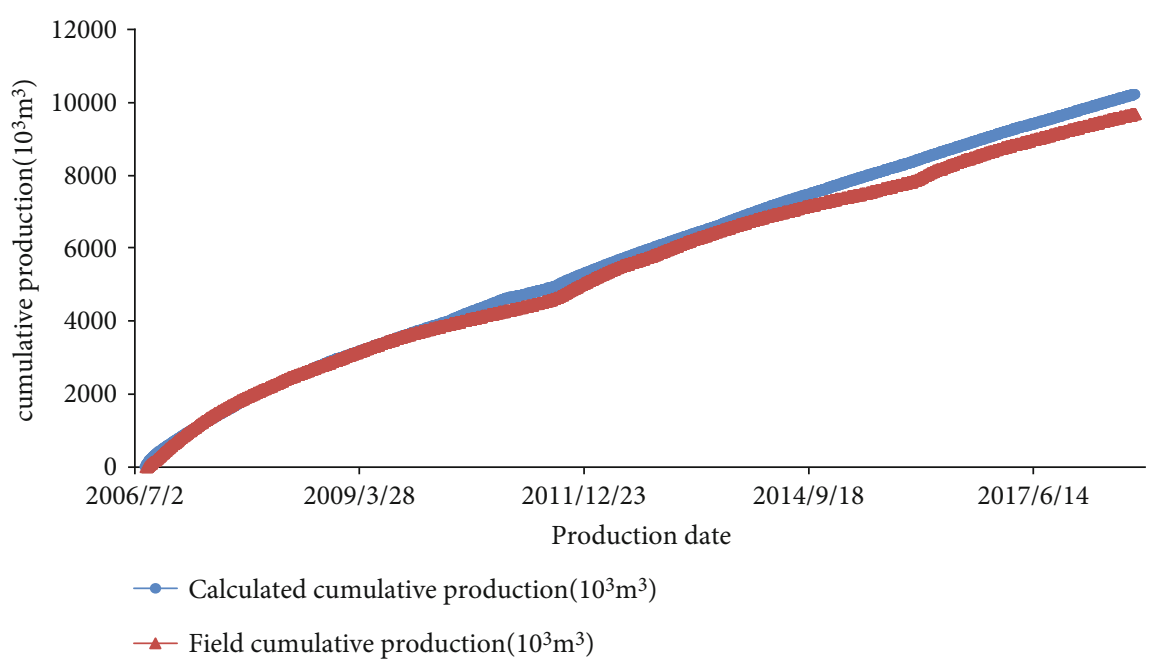

(c) Cumulative gas production history fitting

FIGURE 12: History match result. 
was the half slope in pseudopressure derivative curves on the log-log scale

(6) Desorption and diffusion stage. With the pressure and gas concentration decrease, the desorption becomes more and more obviously. The adsorbed gas in the matrix is gradually desorbed from the coal rock matrix into free gas. The increase in gas concentration in the matrix results in a concentration difference with the natural fracture system, and the gas diffuses from the matrix to the natural fracture system. The derivative curve of the pressure was appearing the " $V$ " shape at this stage. The depth and time of "V" shape are influenced by the desorption coefficient, storage coefficient, cross flow coefficient, and the wellbore storage coefficient. This stage is also the unique pressure response stage of coalbed methane, which reflects the unique adsorption and desorption effect of coalbed methane

(7) Boundary control flow stage. At this stage, the pseudopressure nearly becomes horizontal line with the infinite boundary, the pseudopressure and pseudopressure derivative were upwarp with closed boundary, the pseudopressure derivative falls, and pseudopressure becomes horizontal line with constant pressure boundary

3.2. Comparison of PSS and TSS. Figure 11 showed the transient steady-state and pseudosteady-state sorption and diffusion models with the parameters from Table 2. The pseudosteady diffusion ignores the spatial variation of coalbed methane concentration and focuses on the temporal variation. The pseudosteady-state diffusion assumes that the concentration of methane in the diffusion space is consistent at each time point. This will speed up the calculation, but will lead to calculation errors. The two models show some difference with the same parameters. In the wellbore storage stage, the dimensionless pseudopressure and pseudopressure derivative curves of two models exhibit good agreement with a unit slope straight line. This condition continued to the end of the linear flow stage in SRV region. The PSS model experiences a shorter radial flow in SRV region compared with the TSS model. The dimensionless pseudopressure and pseudopressure derivative curves of PSS model are large than the TSS model at flow in this stage. This is because of the difference of the geometry of two models. The TSS model has the stronger diffuse capacity at earlier stage that can supply to the natural fractured network leading the smaller pressure decline in natural fractured network at this time. This condition will continue to the linear flow in the coal seam, and the gap between the dimensionless pseudopressure derivative curves reaches the peak. In the desorption and diffusion stage, because the desorption and diffusion in the TSS model accomplish instantaneously much of the gas diffusion before, the desorption and diffusion characteristics do not show in this model and continue the reservoir linear until the boundary of the control flow stage. But with the PSS model, the desorption and diffusion reached the peck to supply the natural fractured network leading the smaller pressure decline in natural fractured network. Eventually, the dimensionless pseudopressure derivative curves of PSS model will be under the TSS model; it will continue to the rest of the time. This difference directs us to control the decrease speed of pressure when we develop the coalbed methane; this will use the reservoir energy efficiently. The difference between the PSS and TSS is that PSS was the cube matrix (Figure 4(b)) and the TSS was the spherical matrix (Figure 4(a)). The ultimate difference with the PSS and TSS reflects Equations (9) and (10). Using TSS model and PSS model, we obtain the control equation with Equations (13) and (14).

\section{Field Application}

In the fracturing process of coal, due to the soft coal seam, a lot of fracturing sand will be embedded in the coal seam, which will lead to the obstruction of fracture extension. Most of the fracturing sand is accumulated around the wellbore, forming SRV zone. Surface microseismic monitoring shows that most fractures form only around the wellbore during coal fracturing. Lv et al. [27] based on the information from underground mining in coal mines found most hydraulic fractures extend only 5 to 10 meters.

4.1. Basic Data. The proposed model is used in this paper to validate the model in this paper local in Qinshui Basin. The well was stimulated reservoir volume and hydraulically fractured. Qinshui Basin is located in Shanxi Province of China. Dynamic data mainly include daily gas production data, bottom hole flow pressure data, and other reservoir parameters that represent the geological characteristics of the reservoir (Table 3). The model provided in this paper is used to fit the dynamic parameters.

4.2. History Match Result. Through the principle of time superposition, the analytic solution model is fitted with the actual production data, and the fitting result is finally obtained. Figure 12(a) showed the pressure matching. The average error was $22 \%$. Because of some engineering factors in the well, the data was not fitted well at the end of the match.

The average fitting error of the flow rate shown in Figure 12 (b) is $17 \%$. The flow rate fitting effect is better than the pressure fitting effect. Figure 12(c) showed the actual cumulative gas production and the calculated cumulative gas production of the producing well. The fitting error between the calculated value and field value is small, and the fitting effect is good.

\section{Conclusion}

In this paper, we investigated a stimulated reservoir volume model for finite-conductivity fractured well in a coal seam. With the Laplace transformation, the solutions of this model at a constant production rate or bottom-hole pressure are obtained. Through the above analysis, the following conclusions can be summarized. 
(1) Through a comparison of the equivalent infinite boundary model with infinite-conductivity fracture in homogeneous coal seam, compared with the classical analytical solution, using the new method to solve the fractured model is more accurate and has the better fitting effect with the numerical solution

(2) Compared with the homogeneous coal seam, the composite reservoir has the linear flow and radial flow in SRV region and manifests on the type curves. The value of radial flow in type curves was $1 /(2 \times$ $\left.M_{12} \times C_{D}\right)$

(3) The PSS model experiences a shorter radial flow in SRV region compared with the TSS model. The desorption and diffusion characteristics do not show in this model and continue the reservoir linear until the boundary of control flow stage. Before the desorption and diffusion stage, the pressure of PSS model decreases quickly, but after this stage, the TSS model decreases quickly. Eventually, pressure decrease of PSS model is smaller than the TSS model; it will continue to the rest of the time. This difference directs us to control the decrease speed of pressure when we develop the coalbed methane; this will use the reservoir energy efficiently

(4) The influence of the storage coefficient will be ignored in the line flow because of the flow condition has been improved in the SRV region. The ratio of permeability influences the radial and line flow in SRV region, including the value of radial flow in type curves and the duration time. The well storage coefficient makes the flow stage directly into the matrix methane diffusion phase when it reached a certain value. Conductivity factor mainly influence the early time; after that, the gas from the nature fracture decreases and can flow into the wellbore quickly; the hydraulic fracture is equivalent for the infinity conductivity fractured. The dimensionless SRV region radius mainly influences the end time of the radial flow in SRV region

\section{Symbol}

\section{Symbol in Article}

$r$ : $\quad$ Radius of coalbed methane reservoir, $\mathrm{m}$

$p: \quad$ Pressure, $\mathrm{MPa}$

$t$ : Time variable, $\mathrm{h}$

$t_{a}$ : Agarwal time

$t_{0}$ : Initial time of Agarwal integral, h.MPa/cp

$r_{D m}$ : Dimensionless matrix radius

$R_{m}$ : External radius of the matrix block, $m$

$r_{m}$ : Radial distance of the SRV region, $m$

$\psi: \quad$ Pseudopressure, $\mathrm{MPa}^{2} / \mathrm{cp}$

$L$ : $\quad$ Reference length, in this paper $L$ equal to half of the fracture length, $m$

$x$ : $\quad$ Length of the $x$ coordinates, $\mathrm{m}$

$y$ : Length of the $y$ coordinates, $\mathrm{m}$ $\mu: \quad$ Gas viscosity, MPa $\bullet$

$j: \quad$ Summation variable in the hydraulic fracture system

$k$ : Summation variable in the hydraulic fracture system

$Z$ : $\quad$ Gas deviation factor, dimensionless

$\phi$ : $\quad$ Reservoir porosity, dimensionless and decimal

$c_{g}: \quad$ Coal compressibility, $\mathrm{MPa}^{-1}$

$k$ : $\quad$ Reservoir permeability, D

T: $\quad$ Temperature, $\mathrm{K}$

$V: \quad$ Average matrix gas concentration, $\mathrm{m}^{3} / \mathrm{m}^{3}$

$V_{E}$ : Volume of gas adsorbed per unit volume of the coal grain in equilibrium at pressure $p, \mathrm{~m}^{3} / \mathrm{m}^{3}$

$C$ : Volumetric gas concentration in the microspores, $\mathrm{m}^{3} / \mathrm{m}^{3}$

D: Diffusion coefficient, $\mathrm{m}^{3} / \mathrm{s}$

$p_{L}$ : Langmuir pressure, $\mathrm{MPa}$

$s: \quad$ Laplace variable, dimensionless

$R: \quad$ External radius of matrix, $m$

$L_{f}$ : Half-length of hydraulic fracture, $\mathrm{m}$

$C_{D}$ : Dimensionless wellbore storage coefficient

$C_{f D}$ : Dimensionless fracture conductivity

$M_{12}$ : Ratio of the permeability between the SRV region and outer region

TSS: Abbreviation of the transient steady state

PSS: Abbreviation of the pseudosteady state

cb: Abbreviation of the closed boundary

cpb: Abbreviation of the constant pressure boundary.

\section{Subscripts and Superscripts}

D: Dimensionless property

$e$ : Boundary property

g: Gas property

$t$ : Total property

$L$ : Factor of the Langmuir equation

$w$ : Wellbore property

$i$ : Initial condition

sc: Standard condition

$f$ : Fracture property

1: SRV region property

2: Outer region property

$\sim$ : Image function of Laplace transform

-: Average property

nf: Natural fracture system

hf: Hydraulic fracture system.

\section{Intermediate Variable}

: $\sigma=p_{L} V_{L} p_{i}^{2} q_{D} /\left(p_{L}+p\right)\left(p_{L}+p_{i}\right)\left(p_{i}+p\right)$

$: \Lambda=\varphi \mu c_{g}+\left(p_{s c} T \mu z / T_{s c} q_{D} p_{i}^{2}\right)$

: $\omega=\varphi \mu c_{g} / \Lambda$

$: \tau=R^{2} / D$

$: \lambda=k \tau / \Lambda L_{f}^{2}$

: $\gamma=\sqrt{f(s)}$.

\section{Dimensionless}

: $\psi_{D}=\left(\pi k h T_{s c} / p_{s c} q_{s c} T\right)\left(\psi_{i}-\psi\right)$

: $t_{D}=k t / \Lambda L_{f}^{2}$

: $L_{D}=L / L_{f}$. 


\section{Data Availability}

The verification data in this paper can be found in this paper: Anbarci and Ertekin [1] A comprehensive study of pressure transient analysis with sorption phenomena for single-phase gas flow in coal seams, SPE Annual Technical Conference and Exhibition of the Society of Petroleum Engineers, New Orleans, Louisiana, September 23-26. The rest of the data are all original; if you need any data in the article, please send me an email, Email address: lichen1125@foxmail.com.

\section{Conflicts of Interest}

The authors declare that they have no conflicts of interest.

\section{References}

[1] K. Anbarci and T. Ertekin, "A comprehensive study of pressure transient analysis with sorption phenomena for singlephase gas flow in coal seams," in Paper SPE 20568-MS Presented at the SPE Annual Technical Conference and Exhibition, New Orleans, Louisiana, USA, 1990.

[2] K. Anbarci and T. Ertekin, "Pressure transient behavior of fractured wells in coalbed reservoirs," in Paper SPE 24703MS Presented at the SPE Annual Technical Conference and Exhibition, Washington, D.C., USA, 1992.

[3] J. E. Warren and P. J. Root, "The behavior of naturally fractured reservoirs," Society of Petroleum Engineers Journal, vol. 3, no. 3, pp. 245-255, 1963.

[4] A. De Swaan, "Analytic solutions for determining naturally fractured reservoir properties by well testing," Society of Petroleum Engineers Journal, vol. 16, no. 3, pp. 117-122, 1976.

[5] H. Kazemi, J. R. Gilman, and A. M. Eisharkawy, "Analytical and numerical solution of oil recovery from fractured reservoirs with empirical transfer functions (includes associated papers 25528 and 25818)," SPE Reservoir Engineering, vol. 7, no. 2, pp. 219-227, 1992.

[6] W. J. Mcguire and V. J. Sikora, "The effect of vertical fractures on well productivity," Journal of Petroleum Technology, vol. 12, no. 10, pp. 72-74, 1960.

[7] R. Raghavan, G. V. Cady, and H. J. Ramey, "Well-test analysis for vertically fractured wells," Journal of Petroleum Technology, vol. 24, no. 8, pp. 1014-1020, 1970.

[8] G. R. King, T. Ertekin, and F. C. Schwerer, "Numerical simulation of the transient behavior of coal-seam degasification wells," SPE Formation Evaluation, vol. 1, no. 2, pp. 165-183, 1986.

[9] R. Jiang, X. Liu, X. Wang, Y. Gao, and Y. Huang, "Unsteady productivity model for multi-branched horizontal wells in coalbed methane reservoir," Petroleum Geology and Recovery Efficiency, vol. 27, no. 3, pp. 48-56, 2020.

[10] A. C. Gringarten Jr., H. J. Ramey, and R. Raghavan, “Applied pressure analysis for fractured wells," Journal of Petroleum Technology, vol. 27, no. 7, pp. 887-892, 1975.

[11] H. Cinco-Ley, V. F. Samaniego, and A. N. Dominguez, "Transient pressure behavior for a well with a finite-conductivity vertical fracture," Society of Petroleum Engineers Journal, vol. 18, no. 4, pp. 253-264, 1978.

[12] H. Cinco-Ley and H. Z. Meng, "Pressure transient analysis of wells with finite conductivity vertical fractures in double porosity reservoirs," in Paper SPE 18172-MS Presented at the 63rd Annual Technical Conference and Exhibition of the Society of Petroleum Engineers, Houston. Texas, USA, 1988.

[13] C. R. Clarkson, C. L. Jordan, D. Ilk, and T. A. Blasingame, "Production data analysis of fractured and horizontal CBM wells," in Paper SPE 125929-MS Presented at the SPE Eastern Regional Meeting, Charleston, West Virginia, USA, 2009.

[14] Y. Zhao, L. Zhang, G. Feng, B. Zhang, and B. Kang, "Performance analysis of fractured wells with stimulated reservoir volume in coal seam reservoirs," Oil and Gas Science \& Technology, vol. 71, no. 1, pp. 1-28, 2016.

[15] J. Wang, A. Jia, Y. Wei, W. Luo, and H. Yuan, "Semi-analytical simulation of transient flow behavior for complex fracture network with stress-sensitive conductivity," Journal of Petroleum Science and Engineering, vol. 171, no. 2018, pp. 1191-1210, 2018.

[16] J. Wang, A. Jia, and Y. Wei, “A generalized framework model for simulating transient response of a well with complex fracture network by use of source and green's function," Journal of Natural Gas Science and Engineering, vol. 55, no. 2018, pp. 254-275, 2018.

[17] D. Huang, J. Yang, H. Yu, and W. Li, "Study on production decline law of multilateral horizontal well in coalbed methane reservoirs," IOP Conference Series: Earth and Environmental Science, vol. 300, no. 2, pp. 1-4, 2019.

[18] Q. Zhu, H. Du, Q. Hu, B. Fan, J. Wang, and J. Yu, “Automatic trend tracking model for coalbed methane production forecast," Journal of Physics: Conference Series, vol. 1894, no. 1, pp. 1-5, 2021.

[19] X. Yan, S. Zhang, S. Tang, Z. Li, and J. Wang, "A prediction model for pressure propagation and production boundary during coalbed methane development," Energy \& Fuels, vol. 35, no. 2, pp. 1219-1233, 2021.

[20] R. Jiang, X. Liu, and X. Wang, "Transient pressure analysis of multilateral horizontal well in coal bed methane reservoir with two regions," Journal of Xi'an Shiyou University (Natural Science Edition), vol. 35, no. 4, pp. 53-62, 2020.

[21] J. Wu, J. Zhang, C. Chang, and W. T. W. Xie, "A model for a multistage fractured horizontal well with rectangular SRV in a shale gas reservoir," Geofluids, vol. 2020, no. 1, Article ID 8845250 , p. $18,2020$.

[22] X. Shang, Z. Zhang, Y. Niu, X. Yang, and F. Gao, “Analytical solutions for gas-water two-phase flow in multiseam coalbed methane production," Geofluids, vol. 2021, no. 8, Article ID 6690218, p. 15, 2021.

[23] Q. Tian, Y. Cui, W. Luo, P. Liu, B. Ning, and E. Sciubba, "Transient flow of a horizontal well with multiple fracture wings in coalbed methane reservoirs," Energies, vol. 13, no. 6, 2020.

[24] R. Al-Hussainy, H. Jr, and P. B. Crawford, "The flow of real gases through porous media," Journal of Petroleum Technology, vol. 18, no. 5, pp. 624-636, 1966.

[25] R. G. Agarwal, ""Real gas pseudo-time" - a new function for pressure buildup analysis of MHF gas wells," in Paper SPE 8279-MS Presented at SPE Annual Technical Conference and Exhibition, Las Vegas, Nevada, USA, 1979.

[26] X. Li, D. Zhang, and S. Li, “A multi-continuum multiple flow mechanism simulator for unconventional oil and gas recovery," Journal of Natural Gas Science and Engineering, vol. 26, no. 2015, pp. 652-669, 2015.

[27] S. Lv, S. Wang, H. Liu et al., "Analysis of the influence of natural fracture system on hydraulic fracture propagation morphology in coal reservoir," Journal of China Coal Society, vol. 45 , no. 7 , pp. 2590-2601, 2020. 